\title{
Hand eczema-Clinical patterns and role of patch testing
}

Sir,

Hand eczema is one of the most common dermatological disorders caused by various exogenous and endogenous factors. An attempt has been made in the present study to identify the exogenous agents causing hand eczema with the help of standard series of patch testing, and to correlate the clinical pattern of hand eczema in relation to the allergens.

A total number of 50 patients with hand eczema attending the OPD for a period of 15 months were included in the study. These patients had hand eczema with morphological variants confined to hands. Patients in whom a clinical suspicion of psoriasis, lichen planus and fungal infection could not be disproved, as well as those who had widespread eczema in other areas of the body were excluded from the study. The rest of the patients were subjected to patch testing using Indian standard battery approved by CODFI, manufactured and supplied by Systopic Laboratories, New Delhi. The standard procedures for patch testing were 
meticulously followed, taking all precautions. ${ }^{[1]}$

The observations were graded according to the ICDRG recommendations. ${ }^{[2]}$ Among the 50 patients studied 28 (56\%) were males and $22(44 \%)$ were females, the ratio being 1.21:1 which is contrary to most studies where the incidence was higher in females. ${ }^{[3]}$ An overwhelming $64 \%$ of our patients belonged to the $3^{\text {rd }}$ and $4^{\text {th }}$ decades of life which is in concurrence with other studies. ${ }^{[4]}$

Among the females, housewives were the most common occupational group (68.2\%) and this is because of the variety of agents that they come in contact which may act either as irritants or allergens in addition to the trauma of rubbing and scrubbing. ${ }^{[5]}$ Of the males, $53.6 \%$ were skilled or semi-skilled workers like mechanics, engineers, masons and cooks. The contact with water, which is hypotonic, and the dissolution of the surface lipids by detergents or solvents, may be the reason for a higher incidence of contact allergy in people involved in the above occupations. There was an overlap of signs and symptoms but scaling was the most common presentation (82\%), pruritus and dryness being the most common symptom (76\%).

A positive patch test was seen in $82 \%$ of our patients which is high when compared with other studies. Patch testing has yielded positive results ranging from $50 \%$ to $92.5 \%$ in other studies. ${ }^{[6]}$ Potassium dichromate was the commonest sensitizer testing positive in $26 \%$ of the patients while nickel was the next common testing positive in $18 \%$ of the patients. The high positivity for potassium dichromate is explainable by its presence in detergents and cements. ${ }^{[7]}$

An attempt was made to correlate the clinical patterns and causative agents by adopting the odds ratio. The odds ratio of discoid pattern of lesions and cobalt was highest at 11, and that with balsam of Peru was 7.33.

We encountered a high degree of patch test positivity in our patients and the Indian standard series proved to be very useful, but lacking in certain cases like hand eczema in housewives. Housewives formed the bulk of our study group and a high degree of sensitivity to vegetables has been established in the past. ${ }^{[8]}$ Inclusion of the extracts of common vegetables and fruits in the series would be of immense value. A specific patch test series for the hands as in footwear series or textile series is suggested.

Nanda B. Kishore, A. D. Belliappa, Narendra J. Shetty, D. Sukumar, S. Ravi Department of Dermatology, Venereology and Leprosy, Fr. Muller Medical College, Kankanady, Mangalore, India

Address for correspondence: Dr. Nanda B. Kishore, H.O.D. Dept of Dermatology Venereology and leprosy, Fr. Muller Medical College, Kankanady, Mangalore - 575 002, India. E-mail: sysantosh@yahoo.com

\section{REFERENCES}

1. Shehade SA, Beck MH, Hiller VF. Epidemiological survey of standard series patch test results on day 2 and day 4 readings. Contact Dermatitis 1991;24:119-22.

2. Fischer T, Maibach HT. Patch testing in allergic contact dermatitis: An update. In: Occupational and industrial dermatology. Chicago: Year Book Medical; 1987. p. 190-210.

3. Bajaj AK. Contact Dermatitis Hands. Indian J Dermatol Venereol Leprol 1983;49:195-9.

4. Lantinga H, Nater JP, Coenraades PJ. Prevalence, incidence and course of eczema on the hand and forearms in a sample for the general population. Contact Dermatitis 1984;10:35-40.

5. Glickman FS, Silvers SH. Hand Eczema and Atopy in Housewives. Arch Dermatol 1967;95:487-9.

6. Huda MM, Paul UK. Patch testing in contact dermatitis of hand and feet. Indian J Dermatol Venereol Leprol 1996;62:361-2.

7. Garcia PA, Martin PA, Sanchez MA. Chrome content in bleaches and detergents. Its relationship to hand dermatitis in women. Acta Derm Venereol 1973;53:353-7.

8. Singh G, Singh KK. Contact dermatitis of hands. Indian J Dermatol Venereol Leprol 1886;52:152-4. 